\title{
IT-Enabled Organizational Transformations To Achieve Business Agility
}

One-Ki (Daniel) Lee, University of Massachusetts Boston, USA

\begin{abstract}
There has been increasing attention on organizational dynamic capabilities as the driving forces of superior firm performance in today's turbulent business environment. The objective of this study is to develop a theoretical perspective that explains how firms achieve business agility from their deployment and utilization of information technologies (IT). Drawing upon the organizational learning literature, the study distinguishes two distinctive modes of organizational IT management, i.e., IT exploration and IT exploitation. The internal processes of agility creation from the two modes of IT management activities are explained drawing upon IT-enabled organizational transformations, either through disruptive or incremental innovations. Firm's strategic posture and environment conditions are also considered as factors affecting these transformational processes.
\end{abstract}

Keywords: IT Management; Exploration; Exploitation; Organizational Transformation; Agility

INTRODUCTION

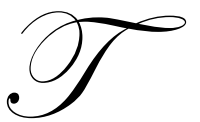

he role of IT in firms' superior performance is a key issue for both academics and practitioners in the fields of business and IT management. Although IT is commonly recognized as a strategic resource for contemporary business competition, there is an ongoing controversy regarding whether or not investing in IT actually leads to better firm performance. This controversy is generally known as the IT productivity paradox (Brynjolfsson 1993, Carr 2003). Carr (2003) argues that as IT's power and ubiquity grows, its strategic importance diminishes, owing to the trend of IT commoditization. As several researchers point out, however, the paradoxical problem in organizational IT value might be a matter of how to actually manage IT, not a matter of IT itself (Bharadwaj 2000, Devaraj and Kohli 2003), and/or a matter of how to measure organizational IT impacts (Barua and Mukhopadhyay 2000). Adopting these arguments, first, this study investigates organizational IT management activities, i.e., IT deployment and utilization, and the capability of these activities as sources of organizational IT value, rather than merely focusing on organizational investments in specific IT assets (Bharadwaj 2000). Second, to address the issue of measuring IT impact, this study adopts a multistage approach that examines intermediate outcomes of IT impact, instead of investigating the direct impact of IT on firm performance. When considering today's highly turbulent business environment, this study focuses on business agility as an intermediate outcome of organizational IT activities and their capabilities (Sambamurthy et al. 2003).

Business agility is a firm's high-level, dynamic capability to respond rapidly to environmental dynamics, by allowing the firm to flexibly assemble the requisite assets, knowledge, and business relationships at great speed (Sambamurthy et al. 2003). IT is a crucial part of organizational infrastructure (Weill et al. 2002), and thus understanding how and under what situations IT can create business agility is a vital concern to both academics and practitioners (e.g., Prewitt 2004, Sambamurthy et al. 2003). In the literature, several researchers point out that IT may enable a firm to react quickly to changes in market conditions by helping the firm to undertake strategic changes when necessary (e.g., Bharadwaj 2000, Sambamurthy et al. 2003, Wheeler 2002). In particular, Sambamurthy et al.'s (2003) seminal paper provides a theoretical foundation for understanding the nomological network of influence among a firm's IT, business agility, and competitive outcomes. Although this body of literature provides a strong foundation for understanding the relationship between IT and business agility, the underlying mechanisms of IT-enabled agility creation have not been satisfactorily explained because of several shortcomings in this literature. First, prior studies mainly focus on high-level components of the nomological 
network, and thus they have limitations in describing the internal processes through which a firm can achieve ITenabled business agility. Second, prior studies tend to view organizational IT activities as a black box and only highlight the IT assets which a firm possesses (Devaraj and Kohli 2003). Thus, the understanding of the locus of organizational IT value is blurred. Third, although environmental factors may influence the relationship between IT and firm performance (Wade and Hulland 2004, Wheeler 2002), studies that investigate the role of environmental factors in realizing organizational IT value are lacking in the extant literature.

This study aims to fill these gaps by investigating the internal processes whereby a firm creates business agility by employing IT in different environmental situations. Two central questions address this research objective: (1) What are the different mechanisms of deploying and utilizing IT resources to create business agility?; (2) Under what conditions can each of these mechanisms create business agility?

\section{LITERATURE REVIEW}

This section will review central issues in investigating organizational IT value in terms of the following two perspectives: (1) locus of IT impact, and (2) intermediate outcome of IT impact.

\subsection{Locus of IT Impact}

Prior studies on organizational IT value suggest various factors as the driving forces of organizational IT impacts. On the basis of a review of extant literature, this study focuses on three potential factors to be considered together in investigating organizational IT impacts, which include IT management, IT complementarities, and environmental contingency.

\subsubsection{Organizational IT Resources and IT Management}

A resource-based view (RBV) is a central theoretical approach in the literature for understanding the locus of organizational IT impacts. According to RBV, organizational resources that are valuable, rare, inimitable, and non-substitutable (so-called VRIN attributes) are viewed as potential sources of organizational competitive outcomes (Barney 1991). By applying this perspective to organizational IT impacts, researchers consider IT resources, e.g., hardware, software, IT personnel, relationship assets, and know-how, as strategic sources for superior firm performance (Davenport and Short 1990, Wade and Hulland 2004). Studies that highlight IT resources focus on the idiosyncratic values of these IT resources in creating business value.

Although traditional IT impact studies highlight the strategic value of individual IT resources, recent studies focus on the organizational capability to manage these IT resources. Recent studies contend that technologies per se do not provide sustained value, because competitors can easily duplicate IT resources (Mata et al. 1995). Studies within this stream of research focus on a firm's deployment and utilization of IT resources, i.e., IT management, as the source of idiosyncratic IT value (Bharadwaj 2000, Tippins and Sohi 2003). Keen (1993) argues that when every leading firm in an industry has access to the same IT resources, how these IT resources are managed will determine an organization's competitive advantage or disadvantage. In other words, a firm's distinguishable ways of managing its IT activities can be thought of as a source of sustainable competitiveness. This shift of theoretical focus from IT resources to IT management regarding the locus of organizational IT impacts is consistent with a strategic management perspective, in which a firm's management capabilities are thought to be idiosyncratic and thus less imitable (Grant 1996). Following this perspective, this study posits that in studying organizational IT impacts, it is important to investigate the area of IT management, rather than merely investigating the effect of IT resources. In this study, IT management is conceptualized as a firm's organizational activities to deliver IT services and products to the firm through assembling, integrating, and deploying IT resources (Bharadwaj 2000).

\subsubsection{IT Complementarities}

Although early IT impact studies tend to isolate IT factors by focusing on their unique value, recent IT impact studies take into account the copresence of other non-IT factors when evaluating positive IT impact (e.g., Barua and Mukhopadhyay 2000, Dedrick et al. 2003). These studies are based on the IT complementarity 
perspective. According to Tanriverdi (2006), two activities are complementary if performing one increases the benefits of performing the other. Studies within this stream of research propose to investigate the synergetic interactions between IT factors and non-IT factors when determining the contribution of IT to organizational outcomes. For example, although Dedrick et al. (2003) show that IT can have a positive impacts at the firm level, such impacts vary by other organizational factors, such as decentralized decision-making systems, job training, and human capital. Moreover, since a firm's IT value depends on the processes in which IT is used (Barua and Mukhopadhyay 2000), it may be difficult to isolate IT factors when investigating their impact within a firm. Following this perspective, this study takes into account other non-IT factors, in particular a firm's strategic posture, in investigating organizational IT impacts. Sambamurthy et al. (2003), for example, argue that a firm's entrepreneurial stance is vital in continually shaping innovation and competitive actions and thus create business agility in combination with organizational IT resources.

\subsubsection{Environmental Factors}

As Bharadwaj (2000) points out, failure to consider other environmental factors that can affect IT's impact on firm performance can be a potential cause of the IT productivity paradox. In particular, Wade and Hulland (2004) suggest investigating a firm's environmental situation as a potential factor that can affect the relationship between IT and firm performance. Wheeler (2002) also argues that various IT activities are required to support different strategies, as environmental dynamism varies. These arguments are consistent with Eisenhardt and Martine's (2000) argument that firms under different environmental dynamisms require different types of organizational routines to tap emerging opportunities and uncertainties. In line with these arguments, this study posits that such environmental contingency factors, in particular environmental dynamism, need to be considered to better understand the various mechanisms for organizational IT value creation.

\subsection{Intermediate Outcomes of IT Impact}

Brynjolfsson (1993) points out that the IT productivity paradox could be caused by an examination of improper outcomes and a lack of consideration of lag-time for IT impact creation. To address these issues, several researchers suggest a multistage approach to examine intermediate-level outcomes of IT impact before examining organization-level outcomes (e.g., Barua and Mukhopadhyay 2000, Soh and Markus 1995). One stream of research following the multistage approach suggests examining IT-enabled organizational transformation as an intermediate variable between IT and firm performance (e.g., Davenport 1993). In contrast, another stream of research examines organizational dynamic capability as an intermediate outcome of IT (e.g., Bharadwaj 2000, Sambamurthy et al. 2003, Wheeler 2002). Although the former stream of research, which is more traditional, may have merit for showing how IT impact happens by investigating the occurring processes (Soh and Markus 1995), the latter stream of research, which is more emerging, may have merit for explaining why some firms exhibit superior performance under turbulent business environments (Sambamurthy et al. 2003). The two streams of the research addressing intermediate IT impact, though distinct, may be highly interdependent, because organizational capability and business processes/routines are closely related (Winter 2000). Therefore, the two streams of research can theoretically complement each other in explaining why and how IT can create superior firm performance under today's environmental dynamics.

\subsubsection{IT-Enabled Organizational Transformations}

Early studies that highlight intermediate IT impacts suggest examining IT-enabled organizational transformation as an intermediate outcome (e.g., Dedrick et al. 2003, Teo et al. 1997, Venkatraman 1994). According to Dedrick et al. (2003), IT is not simply a tool for automating existing processes, but, more importantly, it is an enabler of organizational changes that can lead to additional productivity gains. Studies in this stream focus on IT impact on business processes, such as business process redesign and/or improvement, as intermediate processes of IT-enabled organizational innovation (Davenport 1993). For example, Mukhopadhyay and Kekre (2002) examine the impact of electronic-data-interchange (EDI) technology on the order-processing cycle for both suppliers and customers. Studies in this stream of research mainly highlight two types of organizational transformation in terms of IT-enabled process innovation: one type of IT-enabled organizational transformation can be characterized as radical process change (Davenport 1993, Lyytinen and Rose 2003), and the other type involves 
incremental changes aimed at improving the efficiency and effectiveness of businesses processes (Davenport and Short 1990). Drawing upon these perspectives, the two types of IT-enabled organizational transformation can be defined as disruptive transformation and incremental transformation, respectively.

A disruptive transformation refers to the adoption or creation of a process that is new to an industry and thus leads to radical or revolutionary change of business processes (Davenport 1993). A firm can replace its traditional processes with new processes and enable new organizational innovations (Lyytinen and Rose 2003, Venkatraman 1994). This disruptive type of organizational transformation can be promoted by aggressive technology policies and new technologies to the adopters (Ettlie et al. 1984). By streamlining a firm's value chain from its suppliers to customers, for example, the early implementation of EDI was thought to initiate radical innovations that fundamentally changed the way of conducting its business operations (Larsen 1993). In contrast, incremental transformation can be seen as a continuous process of improvement and business-process modification (Davenport 1993). This type of organizational transformation can enable a firm to enhance the efficiency and effectiveness of its existing business processes. In particular, according to Davenport and Short (1990), IT can lead to incremental process innovations or improvements by providing easy access of information and helping task coordination. For example, the automation of checking customers' financial status is considered an IT-enabled incremental innovation that do not change the way of conducting the specific task in the banking industry (Larsen 1993). It needs to be highlighted that these two types of IT-enabled organizational transformation may involve different organizational strategies and structural focuses (Ettlie et al. 1984).

\subsubsection{IT-Enabled Business Agility}

Researchers are becoming more interested in the strategic role of high-level organizational capabilities that enable a firm to flexibly reconfigure business resources and stimulate competitive actions as the competitive environment of contemporary business becomes more intensive and the speed of environmental change increases (Eisenhardt and Martin 2000). These high-level organizational capabilities are known as organizational dynamic capabilities, e.g., organizational learning capability (Tippins and Sohi 2003), cross-functional capability (Grant 1996), reconfigurability (Pavlou and El Sawy 2006), and business agility (Sambamurthy et al. 2003). Organizational dynamic capabilities are believed to enable a firm to renew its competitiveness by dynamically combining and assimilating internal and external resources (Eisenhardt and Martin 2000, Grant 1996). In particular, since contemporary organizations need to detect and seize market opportunities with speed and surprise, a firm that can respond rapidly and flexibly to environmental dynamics is likely to perform better. This specific type of organizational dynamic capability, known as business agility, enables a firm to flexibly assemble requisite assets, knowledge, and business relationships (Sambamurthy et al. 2003).

According to Lucas and Olson (1994), IT can make a firm flexible by changing the boundaries of where its tasks are accomplished and by removing constraints on when tasks are performed. In particular, IT has been discussed as a potential enabler of business agility, because organizational IT is the digitized platform of business processes and knowledge within a contemporary firm (Sambamurthy et al. 2003, Weill et al. 2002). Sambamurthy et al. (2003) argue that such digitized platforms, e.g., Internet computing, enterprise resource planning (ERP), customer relationship management (CRM), and supply chain management (SCM), can permit a firm to react more quickly to customers' changing requirements by enabling the firm to rapidly detect changes and to flexibly alter its market strategies. For example, when customers use network and communication technologies, the firm can deepen its relationship with customers, thus helping the firm to respond quickly to customers' specific needs. This quick response can allow a firm to seize a new opportunity by increasing its customer value through product and service innovations (Ettlie et al. 1984, Sambamurthy et al. 2003). Moreover, by utilizing IT that can provide personalized and customized products and services, such as Internet-based CRM and business intelligence solutions, a firm can become agile in responding to its customers' specific needs (Goranson 1999). This digitized platform also enables a firm to form value-chain collaborations with partners to rapidly develop emerging and untapped market niches. Therefore, IT can create business agility not only through creating new options for information-based products and services, but also by streamlining work processes and building inter-organizational relationships (Sambamurthy et al. 2003). It needs to be emphasized that while existing studies on agility provide strong support for the relationship between IT and business agility, the internal mechanisms for deploying and utilizing IT resources to develop a firm's agility are still under-researched. 


\section{THEORETICAL DEVELOPMENT}

In this section, multiple propositions are developed to explain how firms can develop their agility through different mechanisms of IT-enabled organizational transformations and under what conditions a specific mechanism can be materialized.

\subsection{IT Exploration and Exploitation}

This study draws from the organizational learning literature in explaining how a firm deploys and utilizes IT resources to generate organizational benefits. According to March (1991), exploration refers to an organizational experimentation with new alternatives and pursuit of knowledge about unknown opportunities. The precursor to this exploration is simply desire, the wish to discover something new. Specifically, when relating this concept to organizational IT management, this study highlights a firm's capability to deploy and experiment with new, emerging information technologies and applications. Exploitation, in contrast, is considered to be the development and use of things already known through the refinement and extension of existing resources and knowledge (March 1991). Based on these theoretical perspectives, this study distinguishes two modes of IT management activities: IT exploration and IT exploitation (Subramani 2004). In particular, IT exploration refers to the firm's activities to acquire new information technologies for the firm's existing and future business activities and strategies. On the other hand, IT exploitation refers to a firm's activities to utilize existing and proven information technologies to improve existing processes or create new ones.

\subsection{Creating Business Agility through IT-Enabled Process Transformations}

\subsubsection{IT Exploration and Disruptive Transformation}

When a firm excels in evaluating the strategic future value of emerging IT resources, such as specific technologies and application systems, it is likely to adopt the IT resources that its rivals have not yet explored. The adoption of new, preemptive IT resources can significantly promote revolutionary changes in business processes (Ettlie et al. 1984). This innovative deployment of emerging IT products and services is also known to bring a firm new business values by redefining its business scope (Venkatraman 1994). According to Lyytinen and Rose (2003), the disruptive nature of new technologies, such as Internet computing, can initiate radical changes in existing business processes. The following cases from the literature on organizational IT adoption illustrate how a firm's IT exploration enables its radical process redesign and thus enhances its agility.

Case 1. Baxter Healthcare's ASAP system, an automatic purchasing system based on tracking customer's inventory, is an example of radical process transformation by new IT exploration (Venkatraman and Short 1992). This industry-new system initiated a disruptive redesign of its ordering and procurement processes (Teo et al. 1997). These radical transformations enhanced its capability to respond to customer order, inventory change, and emerging needs at great speed. Moreover, based on this preemptive strategic use of an IT resource in its industry, Baxter could start new business, i.e., material management consultation (Teo et al. 1997), and, as a result, this company became more agile to respond to fast change and severe competition in its marketplace.

Case 2. In the late 1990s, Skandia, a life and casualty insurance company named among the world's top 20 insurance companies, detected new market opportunities in global financial service: (1) an emerging customer group, internationally mobile, with sizable financial assets, and with regular needs to manage its varied accounts and investments from international locations; and (2) an emerging need for Internet-based financial services by non-traditional actors, such as supermarkets and employee unions, and a number of small- to mid-size local and regional banks (Alexandersen et al. 2003). The Skandia Group capitalized on these emerging opportunities within a short period by adopting a radically innovative approach, i.e., the LEGO-like integration of pre-designed and existing third-party financial-service components, in developing its global financial system. This enabled Skandia to explore novel service modules achieved from external partners, such as IT vendors and external financial-service providers. Skandia's strong capability to deploy new IT resources from its external sources enabled the firm to rapidly capture emerging market opportunities (Alexandersen et al. 2003). 
The Baxter case suggests that a firm's IT exploration can bring the firm a capability to respond to its market dynamics, i.e., agility, by initiating its disruptive transformations in organizational structures (Teo et al. 1997). Likewise, Skandia's IT exploration could realize its novel business model (Alexandersen et al. 2003). Such disruptive transformations in organizational structure and services can allow a firm to be more capable and agile in responding to its business environment (Lucas and Olson 1994). Reflecting on these cases and their relevant arguments, this study suggests the following Proposition 1:

Proposition 1. A firm's IT exploration can lead to business agility through IT-enabled disruptive transformations, which involve radical process redesign and/or structural changes of the firm, such as altering service structure and business scope.

\subsubsection{IT Exploitation and Incremental Transformation}

According to Ellie et al. (1984), although an aggressive, radical technology policy may initiate disruptive transformations, such policy may not significantly motivate incremental transformations, such as process improvement. Instead, a firm's efficacious utilization of existing IT resources, i.e., IT exploitation in this study, may enable the firm to improve its business processes. This is mainly because a firm's business processes are the IT-use processes under today's digitized economies (Sambamurthy et al. 2003). In particular, most business processes in contemporary business environments are highly dependent upon information processing. Hence, the use of IT resources is pervasively embedded in business processes to support requisite information processing (Devaraj and Kohli 2003, Soh and Markus 1995). Therefore, increasing efficiency in utilizing IT resources can lead to an improvement of business processes that relate to IT resources. This can be viewed as an IT-enabled incremental transformation. The following case illustrates the mechanism of a firm's incremental transformations of its services and operations that are enabled by IT exploitation.

Case 3. Con-Way Transportation Services had a strong capability to reuse existing software components to build new IT services (Prewitt 2004). This company's continuous adjustment and novel combination of existing software components could improve its customer service processes and rapidly adapt to dynamic requirements. This was mainly because of its standardized IT infrastructure and the strong partnership between its IT department and business side. Its exploitation of existing IT resources was a driving force of its incremental process innovations to adapt to changes in its customers' needs, and thus this firm could achieve agility (Prewitt 2004).

In addition to such IT-enabled incremental innovations, the appropriate integration of existing IT resources with key business processes is thought to improve the speed of response to the market's specific needs (Prewitt 2004, Sambamurthy et al. 2003) and thus to enable firms to seize new opportunities by improving their existing ways of doing things (Ettlie et al. 1984). In particular, a proper integration of computing, communications, and content technologies into business processes can enable a firm to achieve significant opportunities to improve how quickly and accurately it responds to market changes, thus making a firm agile in terms of internal operations (Lucas and Olson 1994, Sambamurthy et al. 2003). These arguments are formally stated in Proposition 2:

Proposition 2. A firm's IT exploitation can lead to business agility through IT-enabled incremental transformation, which involves the enhancement of existing business processes enabled by the development of better IT services and/or the appropriate integration of existing IT resources with business processes.

\subsubsection{Strategic Posture as an IT Complementarity Factor}

In addition to the disruptive transformations enabled by IT exploration, a firm may have another driving force of organizational radical innovations. According to Reinmoeller and van Baardwijk (2005), a firm's innovation strategies can determine the way the firm uses its resources. For example, entrepreneurship is an essential factor in defining a firm's innovation strategies. Entrepreneurship can be characterized as seeking to create new ideas and resources beyond an organization's boundaries. Entrepreneurial actions are driven by autonomous units, usually supported by top management. Since entrepreneurial actions lie at the core of radical or breakthrough innovation, they lead to new business and creativity in a firm's competitive activities (Sambamurthy et al. 2003). 
Therefore, this strategic posture of a firm is likely to affect IT-enabled disruptive organizational transformation particularly by stimulating innovative utilization of existing IT resources to implement new IT products/services. The following Merrill Lynch case (Levinson 2004) illustrates how a firm's entrepreneurship can influence the ITenabled organizational transformation process.

Case 4. At the height of the corporate scandals and the 2002 economic downturn, Merrill Lynch embarked on a restructuring of its IT operation. Its IT had been set up in vertical structure across three business groups: asset management, institution, and retail. Since each of these business groups had its own IT staff and assets, Merrill Lynch did not get any economies of scale; technologies were redundant; and people and processes proliferated. Top management decided to centralize its IT into a global-services organization and to deliver it to the business as a utility. In other words, each business group would tell IT how much computing power it needed, and IT would charge the business on a monthly basis for what it used. Its utility model provides a mechanism for throttling IT services (e.g., storage and processing power) up or down depending on business demand. Agility plays a role because it "allows the businesses to change the pricing and the internal profit-and-loss dynamics of their businesses so they can respond much more quickly to changes in the marketplace" (Levinson 2004).

While Merrill Lynch was still exploiting its existing IT resources, top management's insight in restructuring the distributed IT resources across multiple business units generated a radical change in its IT services and corresponding business processes, i.e., disruptive transformation, to support its business needs. This, in turn, led to business agility (Levinson 2004). The top management's insight can be viewed as an aggressive, proactive strategic posture which is marked by a strong emphasis on technological leadership and radical new product/service innovations (Ozsomer et al. 1997). Hence, this strategic posture may explain a firm's activities and outcomes regarding IT resource utilization beyond its IT units. In particular, the involvement of a strategic posture factor changed the nature of the relationship between IT management and organizational transformation in such a way that its proactive strategic posture initiated a disruptive transformation along with IT exploitation. These arguments are formally stated in Proposition 3:

Proposition 3. The involvement of a proactive strategic posture in exploitative IT resource deployment and utilization to deliver a firm's IT products/services can also create business agility through disruptive transformation.

\subsection{Conditional Value of IT-Enabled Process Transformation}

The two distinctive types of organizational transformation that are enabled by different modes of IT management activities describe the different organizational mechanisms by which firms can create their agility. Furthermore, this study suggests considering environmental factors that contingently affect realization of the proposed mechanisms. According to Wade and Hulland (2004), to react to a fast-changing environment, namely environmental turbulence, firms require different sets of organizational assets and capabilities. Specifically, Eisenhardt and Martin (2000) argue that firms under different levels of environmental dynamism may require different ways of responding to environmental dynamics. In particular, firms under highly dynamic markets rely more on flexible, experiential, and simple processes to deal with unpredictable market needs. In contrast, firms under moderately dynamic markets need more stable, detailed, and analytic mechanisms to achieve predictable outcomes and thus rely more on existing knowledge and linear execution of their business processes. This implies that the internal mechanism to materialize business agility for market changes varies with market dynamism.

By adopting this contingency perspective, Wheeler (2002) argues that firms under highly dynamic markets attach less value to prior knowledge and prefer to adopt new IT resources and knowledge through alliances or joint ventures. Firms under moderately dynamic markets, in contrast, focus more on their existing capability, experience, and processes regarding IT utilization. In particular, a firm's exploration of new IT resources and knowledge can initiate new business value through disruptive transformation. This has a strategic value by creating a first-mover advantage in the competing market (Bharadwaj and Sambamurthy 2005). In addition, according to Lyytinen and Rose (2003), the rapidly and simply changeable processes that will be required for firms in highly dynamic markets (Eisenhardt and Martin 2000) can be achieved by disruptive technologies, such as Internet computing. An 
incremental transformation tactic, however, also can increase a firm's overall capacity for changes, i.e., business agility (Bharadwaj and Sambamurthy 2005). This tactic may have a low risk of failure, but it typically takes a long time. Therefore, under a highly dynamic market, this tactic may not be appropriate. Based on these arguments, this study posits that the level of market dynamism contingently affects the value of each different type of IT-enabled organizational transformation in creating business agility. Thus, Proposition 4 is formulated as follow:

Proposition 4. Under a highly dynamic market condition, the IT-enabled disruptive organizational transformation will lead to business agility, while under a moderately dynamic market condition, the IT-enabled incremental organizational transformation will lead to business agility.

\section{DISCUSSION AND CONCLUSION}

Although attention to the role of IT in a firm's competitive success has been increasing over the past two decades, many questions remain unresolved. Theoretical perspectives in the IT impact literature, such as the resource-based view (RBV), the organizational-transformation perspective (specifically, process innovation), and the dynamic-capability view (DCV), bring different understandings about the locus of and the mechanisms of a firm's IT-enabled competitive success. Consequently, research outcomes of IT impact studies appear to be contradictory. This study aims to provide an integrative theoretical perspective to explain how and why IT can enable a firm to improve its performance under dynamic market conditions. Specifically, reflecting on today's highly competitive and rapidly changing business environments, business agility is highlighted as an intermediate outcome of organizational IT impact. Regarding the locus of IT impact, this study suggests focusing on organizational IT management activities to deploy and utilize IT resources and their distinctive modes, i.e., IT exploration and exploitation. Drawing upon the organizational learning and innovation literature, this study reveals multiple paths for business agility creation: (1) IT-enabled disruptive transformation, in which business agility is created by innovative adoptions of new IT resources; (2) IT-enabled incremental transformation in which business agility is created by utilizing the existing IT resources; and (3) IT-enabled disruptive transformation path initiated by proactive strategic posture to deliver IT products/services, even with IT exploitation. This study further proposes the conditional value of these paths under different levels of environmental dynamism.

As a conceptual study in an organizational context, this study has some potential theoretical and practical limitations. First, a firm may have the capability to learn capabilities (Winter 2000), as is the nature of dynamic capability. This learning capability can generate feedback loops. To focus on the roles of IT with regard to business agility creation, however, this study does not consider self-learning or feedback loops. In future studies, inclusion of such feedback loops will further improve the research perspective. Second, within a firm, the boundaries between the contrasting behavioral patterns, such as disruptive versus incremental and explorative versus exploitative are not always clear. For example, a firm can have both high IT exploration and exploitation capabilities, which is known as IT ambidexterity (e.g., Subramani 2004). Hence, further consideration of potential relationships among them (either synergistic or substituting) will enrich the theoretical arguments. Third, in developing the research propositions, multiple industry cases published in the literature were used as examples. Although these cases provide good insights with regard to the proposed arguments, they may have limitations to fully exemplify the given propositions because of their contextual specifications. Further analysis with dedicated cases or empirical survey data would be useful to validate the proposed model.

Despite the abovementioned limitations, this study holds benefits for both academics and practitioners. In terms of academic contributions, first, this study can enhance understanding of the nature of organizational IT management activities and how they can enable business agility, thus leading to a firm's competitive success. The conceptual expansion of IT management can enrich the development of further research ideas. As Fry (1982) pointed out, a lack of agreement on common understandings for IT-relevant constructs may generate many problems in conceptualization, validation, and eventually research outcomes in IS research. Hence, a theoretical conceptualization of IT management constructs as the locus of IT-enabled organizational transformation can serve as an alternative for a common understanding of this research construct. Second, by taking a contingency approach, this study partly addresses the inconsistent findings of organizational IT impacts in the literature, i.e., IT productivity paradox. Third, through the theoretical development, the central, yet fragmented theoretical perspectives in the literature, such as RBV, process innovation, and $\mathrm{DCV}$, were consolidated to build a more 
comprehensive perspective on organizational IT impacts. Finally, this study provides a theoretical foundation for further empirical studies. In terms of practical contributions, this study offers guidance for practitioners to more strategically and selectively focus their IT investment, depending on their firm's situations, in order to more effectively create business agility.

\section{AUTHOR INFORMATION}

One-Ki (Daniel) Lee is an Assistant Professor in the Department of Management Science and Information Systems at the University of Massachusetts Boston. He received his Ph.D. from the City University of Hong Kong. His research interests include IT-enabled organizational agility, agile project management, knowledge management, IT controls/governance, and social software. His work has appeared in journals such as Communications of the ACM, Information and Management, and Journal of Global Information Management. Lee, One-Ki (Daniel), MS\&IS Department, University of Massachusetts, 100 Morrissey Blvd. Boston, MA 02125. E-mail: Daniel.Lee@umb.edu.

\section{REFERENCES}

1. Alexandersen, C., K. Kumar, J. van Hillegersberg. (2003). Bank-in-a-Box: Skandia's a Agile and Customizable Financial Services Platform. Paper presented at the SIM 2003 Paper Awards Competition.

2. Barney, J. B. (1991). Firm Resources and Sustained Competitive Advantage. Journal of Management, 17(1), 99-120.

3. Barua, A., T. Mukhopadhyay. (2000). Information Technology and Business Performance: Past, Present, and Future. In R. W. Zmud (Ed.), Framing the Domains of IT Management: Projecting the Future through the Past (pp. 65-84). Cincinnati, Ohio: Pinnaflex Educational Resources.

4. Bharadwaj, A., V. Sambamurthy. 2005. Enterprise Agility and Information Technology Management: The CIO's Manifesto: SIM Advanced Practices Council Publication.

5. Bharadwaj, A. S. (2000). A Resource-Based Perspective on Information Technology Capability and Firm Performance: An Empirical Investigation. MIS Quarterly, 24(1), 169-196.

6. Brynjolfsson, E. (1993). The Productivity Paradox of Information Technology. Communications of the ACM, 36(12), 66-77.

7. $\quad$ Carr, N. G. (2003). IT Doesn't Matter. Harvard Business Review, 81(5), 41-49.

8. Davenport, T. H. (1993). Process Innovation: Reengineering Work through Information Technology. Cambridge, MA: Harvard Business School Press.

9. Davenport, T. H., J. E. Short. (1990). The New Industrial Engineering: Information Technology and Business Process Redesign. Sloan Management Review, 31(4), 11-27.

10. Dedrick, J., V. Gurbaxani, K. L. Kraemer. (2003). Information Technology and Economics Performance: A Critical Review of the Empirical Evidence. ACM Computing Surveys, 35(1), 1-28.

11. Devaraj, S., R. Kohli. (2003). Performance Impacts of Information Technology: Is Actual Usage the Missing Link? Management Science, 49(3), 273-289.

12. Eisenhardt, K. M., J. A. Martin. (2000). Dynamic Capabilities: What are they? Strategic Management Journal, 21(10/11), 1105-1121.

13. Ettlie, J. E., W. P. Bridges, R. D. O'Keefe. (1984). Organizational Strategy and Structural Differences for Radical versus Incremental Innovation. Management Science, 30(6), 682-695.

14. Fry, L. W. (1982). Technology-Structure Research: Three Critical Issues. Academy of Management Journal, 25(3), 532-552.

15. Goranson, H. T. (1999). The Agile Virtual Enterprise: Cases, Metrics, Tools. Westport, Connecticut: Quorum Books.

16. Grant, R. M. (1996). Prospering in Dynamically-Competitive Environments: Organizational Capabilities as Knowledge Integration. Organization Science, 7(4), 375-387.

17. Keen, P. G. W. (1993). Information Technology and the Management Difference: A Fusion Map. IBM Systems Journal, 32(1), 17-39.

18. Larsen, T. J. (1993). Middle Managers' Contribution to Implemented Information Technology Innovation. Journal of Management Information Systems, 10(2), 155-176.

19. Levinson, M. (2004). How to Build an Agile IT Department. CIO Magazine, 17(21). 
20. Lucas, H. C., M. Olson. (1994). The Impact of Information Technology on Organizational Flexibility. Journal of Organizational Computing, 4(2), 155-176.

21. Lyytinen, K., G. M. Rose. (2003). The Disruptive Nature of Information Technology Innovations: The Case of Internet Computing in Systems Development Organizations. MIS Quarterly, 24(4), 557-595.

22. March, J. G. (1991). Exploration and Exploitation in Organizational Learning. Organization Science, 2(1), 71-87.

23. Mata, F. J., W. L. Fuerst, J. B. Barney. (1995). Information Technology and Sustained Competitive Advantage: A Resource-based Analysis. MIS Quarterly, 19(4), 487-505.

24. Mukhopadhyay, T., S. Kekre. (2002). Strategic and Operational Benefits of Electronic Integration in B2B Procurement Processes. Management Science, 48(10), 1301-1313.

25. Ozsomer, A., R. J. Calantone, A. D. Benedetto. (1997). What Makes Firms More Innovative? A Look at Organizational and Environmental Factors. Journal of Business \& Industrial Marketing, 12(6), 400-416.

26. Pavlou, P. A., O. A. El Sawy. (2006). From IT Leveraging Competence to Competitive Advantage in Turbulent Environments: The Case of New Product Development. Information Systems Research, 17(3), 198-227.

27. Prewitt, E. (2004). The Agile 100. CIO Magazine, 17(21).

28. Reinmoeller, P., N. van Baardwijk. (2005). The Link Between Diversity and Resilience. MIT Sloan Management Review, 46(4), 61-65.

29. Sambamurthy, V., A. Bharadwaj, V. Grover. (2003). Shaping Agility through Digital Options: Reconceptualizing the Role of Information Technology in Contemporary Firms. MIS Quarterly, 27(2), 237263.

30. Soh, C., M. L. Markus. (1995). How IT Creates Business Value: A Process Theory Synthesis. Paper presented at the Proceedings of the Sixteenth International Conference on Information Systems, Amsterdam.

31. Subramani, M. (2004). How Do Suppliers Benefit from Information Technology Use in Supply Chain Relationships? MIS Quarterly, 28(1), 45-73.

32. Tanriverdi, H. (2006). Performance Effects of Information Technology Synergies in Multibusiness Firms. MIS Quarterly, 30(1), 57-77.

33. Teo, H.-H., B. C. Y. Tan, K.-K. Wei. (1997). Organizational Transformation Using Electronic Data Interchange: The Case of TradeNet in Singapore. Journal of Management Information Systems, 13(4), 139165 .

34. Tippins, M. J., R. S. Sohi. (2003). IT Competency and Firm Performance: Is Organizational Learning a Missing Link? Strategic Management Journal, 24(8), 745-761.

35. Venkatraman, N. (1994). IT-Enabled Business Transformation: From Automation to Business Scope Redefinition. Sloan Management Review, 35(2), 73-87.

36. Venkatraman, N., J. E. Short. (1992). Baxter Healthcare: evolution from ASAP to Valuelink in the hospital supplies marketplace. Paper presented at the Proceedings of the Twenty-Fifth Annual Hawaii International Conference on System Sciences.

37. Wade, M., J. Hulland. (2004). Review: The Resource-Based View and Information Systems Research: Review, Extension, and Suggestions for Future Research. MIS Quarterly, 28(1), 107-142.

38. Weill, P., M. Subramani, M. Broadbent. (2002). Building IT Infrastructure for Strategic Agility. MIT Sloan Management Review, 44(1), 57-65.

39. Wheeler, B. (2002). NEBIC: A Dynamic Capabilities Theory for Assessing Net-Enablement. Information Systems Research, 13(2), 125-146.

40. Winter, S. G. (2000). The Satisficing Principle in Capability Learning. Strategic Management Journal, 21(10/11), 981-996. 